\title{
ЦИФРОВОЕ ОБЩЕСТВО: НОВЫЕ ВОЗМОЖНОСТИ И СТАРЫЕ УГРОЗЫ
}

\author{
А. А. Деревянченко \\ Московский гуманитарный университет, \\ Д. В. Калинин \\ МИРЭА - Российский технологический университет
}

\begin{abstract}
Аннотация: В статье, представляющей собой доработанный доклад на XV Международной научной конференции «Высшее образование для ХХІ века. Роль гуманитарного образования в контексте технологических и социокультурных изменений», анализируются некоторые тенденции складывающегося в современном мире цифрового общества; показаны возможности и угрозы, возникающие в связи с переходом человечества и России к данному обществу. Особо выделены задачи, стоящие перед системой образования и ее работниками.
\end{abstract}

Ключевые слова: цифровое общество; Интернет; информационные технологии; возможности и угрозы; система образования

\section{DIGITAL SOCIETY: NEW OPPORTUNITIES AND OLD THREATS}

\author{
A. A. Derevyanchenko \\ Moscow University for the Humanities, \\ D. V. Kalinin \\ MIREA - Russian Technological University
}

Аннотация: The article is a revised report at the 15th International Scientific Conference "Higher Education for the 21st Century. The Role of Humanitarian Education in the Context of Technological and Sociocultural Changes." It analyzes some trends of the digital society emerging in the modern world and demonstrates the possibilities and threats arising in connection with the transition of mankind and Russia to this society. The tasks facing the education system and its employees are highlighted.

Keywords: digital society; Internet; information technology; opportunities and threats; education system

\section{Введение}

Целью предлагаемой статьи является анализ возможностей и угроз, происходящей в современном мире цифровой трансформации общества, что можно проиллюстрировать множеством примеров. Ограничимся только двумя. 
Bo-первыХ, в конце второго десятилетия XXI века в Японии разработана концепция формирования цифрового общества, базирующегося на использовании цифровых технологий во всех сферах общественной жизни. Эта концепция общества, получившего название «Общества 5.0», исходит из того, что данному типу обществ предшествовали 4 исторических типа обществ: общество охотников и собирателей, аграрное общество, индустриальное общество и информационное общество («Общество 4.0»). В цифровом «Обществе 5.0» достижения науки и технологий будут работать на благо каждого члена общества (причем в перспективе - не только японского) ${ }^{1}$.

Bo-вторых, 1 декабря 2019 г. граждане Китая могут попадать в интернет только после прохождения процедуры распознавания лица. С точки зрения китайских властей, эта мера необходима для того, чтобы удостоверением личности, необходимом сегодня для доступа во Всемирную сеть, не могли воспользоваться киберпреступники и мошенники. Согласно закону, действующему для всех операторов связи Китая, последние «будут обязаны проверять подлинность удостоверения личности, а технология распознавания лиц позволит установить, является ли человек, подавший заявление на подключение к Сети, фактическим владельцем представленного удостоверения» ${ }^{2}$.

\section{Цифровое общество и его возможности}

Согласно данным агентства We Are Social и сервиса Hootsuite на январь 2019 г. в мире: насчитывалось более 5,11 млрд. уникальных мобильных пользователей (это 67\% всего населения Земли), мировая аудитория интернета составляла - 4,39 млрд. человек (57\% землян), в социальных сетях было зарегистрировано 3,48 млрд. пользователей (45\% жителей Земли). В России число интернет-пользователей на тот же период составило 109,6 млн, это значит, что уровень проникновения интернета находится на отметке в $76 \%{ }^{3}$. Таким образом, исходя их вышеуказанных данных можно утверждать, что более $50 \%$ людей в мире и еще более значительная доля

\footnotetext{
${ }^{1}$ Полхова, Е. (2016) Ниппон Кэйданрэн: за скобками внешнеполитических доктрин [Электронный ресурс] // Российский совет по международным делам. URL: https:// russiancouncil.ru/blogs/Ekaterina-Polkhova/2314/ (дата обращения 4.10.2019).

2 Дуболев, К. (2019) Доступ в интернет в Китае будут предоставлять только после распознавания лица [Электронный ресурc] URL: https://www.km.ru/sciencetech/2019/10/18/internet-v-mire/858273-popast-v-internet-v-kitae-mozhno-budettolko-cherez-s (дата обращения 1.11.2019).

${ }^{3}$ Сергеева, Ю. (2019) Вся статистика интернета на 2019 год - в мире и в России. [Электронный ресурс] // Web-canape. URL: https://www.web-canape.ru/business/vsyastatistika-interneta-na-2019-god-v-mire-i-v-rossii/ (дата обращения 24.10.2019 г.).
} 
Научные труды Московского гуманитарного университета 2019 № 6

населения России живут в формирующемся цифровом обществе.

Понятие формирующегося цифрового общества в социологии пока еще не имеет однозначного толкования. В первом приближении, можно сказать, что это общество, в котором информация и сетевизация, информационно-коммуникационные технологии, локальные и глобальные компьютерные сети играют важнейшую роль в организации и регулировании жизни людей; это общество, в котором цифровое общение и виртуальные сообщества начинают доминировать над живым общением и реальными сообществами. Как подчеркнула Т. Ф. Кузнецова, цифровое общество, «понимаемое как концепт, требует ценностного измерения», благодаря чему «разделение оптимистического и пессимистического взглядов станет в высшей степени контрастным» (Кузнецова, 2018: Электр. ресурс).

Складывание цифрового общества характеризуют следующие тенденции:

1) информационный взрыв, выражающийся в неуклонном возрастании объема информации: в 2018 г., по данным исследования IDC и Seagate Technology, общий объем данных в цифровой вселенной составляет 33 зеттабайта, а к 2025 г. прогнозируется его увеличение до 175 зеттабайт ${ }^{1}$;

2) формирование интернета вещей, представляющего собой разнообразные технологические, производственные, инфраструктурные устройства, приборы, приспособления и т. п., имеющие блоки контроля, передачи информации и управления, подключенные к Интернету. В настоящее время к Интернету уже подключено всего в мире более 22 млрд. устройств ${ }^{2}$. Развитие интернета вещей содержит огромные возможности для мировой и российской экономики. К примеру, опыт Финляндии и Норвегии по использованию технологии «умных домов» и «умных кварталов», с подсоединением к интернету системы как поквартирного, так и централизованного тепло- и энергоснабжения, позволяет на $12-17 \%$ уменьшить расходы на отопление при сохранении неизменной температуры в жилых помещениях. Трудно не согласиться с тем, что «в условиях нашей страны использование Интернета вещей в подобных сферах даст еще более впечатляющий эффект» (Россия и вызовы ..., 2014: 13);

3) человек в цифровом обществе приобретает (в принципе вне соб-

\footnotetext{
${ }^{1}$ Кривошапко, Ю. (2019) Большие данные станут еще больше. [Электронный ресурс] // Российская газета - Федеральный выпуск. № 58(7816). URL: https:// rg.ru/2019/03/17/globalnaia-sfera-dannyh-vyrastet-bolee-chem-v-piat-raz-v-blizhajshiegody.html (дата обращения 27.10.2019).

${ }^{2}$ Интернет вещей, IoT, M2M мировой рынок (2019) [Электронный ресурc] URL: http:// www.tadviser.ru/index.php/Статья:Интернет_вещей,_IoT,_M2M_(мировой_рынок) (дата обращения 29.10.2019).
} 
ственного желания) свое цифровое «я» в виде цифрового досье (цифровая идентификация и аутентификация как одна из основ цифрового общества), которое может содержать даже больше информации о человеке, чем он знает сам о себе ${ }^{1}$. В цифровом обществе каждый индивид оставляет обширную информацию о себе в электронном виде в открытом или условно закрытом доступе: личная информация в социальных сетях, данные о финансовой деятельности, геоданные, рекламные идентификаторы, огромное количество аудио-, фото- и видеофайлов, историй деятельности в различных приложениях и «следы» на сайтах, которыми пользовался человек. Эта информация хранится в фрагментированном виде в больших базах данных (Big Data) различных цифровых сервисов и услуг, имеющих вполне конкретных владельцев. Следовательно, если вы ведете активную жизнь в интернете, то каждое ваше действие с использованием современных сетевых технологий ведет к тому, что вы оставляете так называемый «цифровой след»: поездка с использованием навигатора, ваш маршрут и поведение на дороге, использование голосовых помощников, ваш голос, использование электронных платежных систем, цифровая подпись, потребительские предпочтения, ваши история электронных покупок и потребительская корзина, ваши социальные сети и виртуальные сообщества, ваши интересы, вкусы, связи ничто не остаётся без внимания;

4) появление и распространение в мире нательного (носимого) интернета, или бодинета, имеющего три основных составных части: а) предвестники эры распределенных компьютеров типа очков Google Glass; б) предметы гардероба (одежда, обувь и т. п.), соединенные с интернетом и контролирующие состояние здоровья или иных параметров владельца; в) электронные компоненты микроприспособлений и микроустройств, имплантированные в тело человека: к примеру, «уже около миллиона американцев имеют медицинские имплантаты, подсоединенные к Интернету и в основном связанные с кардиоконтролем, а также с контролем уровня сахара в крови. ...Есть основания полагать, что в ближайшие 5-7 лет встроенные в человеческое тело имплантаты, соединенные с Интернетом, из экзотики превратятся в обыденность практически во всех развитых странах мира» (Россия и вызовы ..., 2014: 15).

Сейчас уже сформировалось поколение, которое родилось и выросло в формирующемся цифровом обществе. Его называют цифровым поколени-

\footnotetext{
${ }^{1}$ Филимонов, В. (2018) Цифровое общество и конец истории. Доклад на XXVI Международных Рождественских чтениях, секция «Актуальные вопросы национального суверенитета России» (Москва, 26.01.2018 г., Российский университет дружбы народов) [Электронный ресурс] // РИА «Катюша, 1 февраля. URL: http://katyusha.org/ view?id=9326 (дата обращения 22.10.2019).
} 
Научные труды Московского гуманитарного университета

2019 № 6

ем, или цифророженным (Деревянченко, 2019: 311). Оно интересно тем, что росло и развивалось в условиях бурного роста информационно-компьютерных технологий и глобальных телекоммуникационных сетей, к которым не было доступа ни у одного из предшествующих поколений. Всё это не могло не повлиять на их физическое и интеллектуальное развитие, психологические особенности и мировосприятие.

\section{О современных угрозах}

Стремительное развитие цифровизации общества влечет за собой не только новые возможности и преимущества, а и ряд старых, но трансформированных угроз, которые необходимо тщательно исследовать, чтобы избежать «конца истории».

Прежде всего, отметим, что, как правило, угрозы, связанные с Интернетом и социальными сетями, сводят к различным видам киберпреступности и даже к кибертерроризму, поэтому первостепенной задачей государств с высоким уровнем компьютеризации и сетевизации населения и бизнеса становится налаживание международного сотрудничества в данной области. Здесь имеется еще одна не всеми осознаваемая угроза - «угроза цифровому суверенитету России, связанная с интернетом вещей. В настоящее время поисковые системы и платформы социальных сетей, такие как Facebook, Twitter и др., позволяют анализировать поведение пользователей, объединяемых в самые различные группы, их предпочтения, активность, связи и т. п. С появлением Интернета вещей такой мониторинг в режиме онлайн может вестись уже не в отношении интернет-активности, а в отношении реальной жизнедеятельности населения, функционирования предприятий» (Россия и вызовы ... , 2014: 14), организации работы городских, управленческих и иных структур, что может подрывать основы деятельности государства. А, возвращаясь к бодинету, укажем, что его возможности с точки зрения осуществления киберпреступлений, включая телесные повреждения, убийства и точечный терроризм также нельзя недооценивать.

Современные способы поиска, восприятия и передачи информации искажают картину мира, делая ее более плоской, но в тоже время емкой в информационном плане. Эмоциональная жизнь, как известно, основана на тактильности, но в условиях цифрового общества осуществляется потеря тактильных ощущений. Количество людей, с которыми человек общается в основном или полностью дистанционно (телефон, электронные письма, чаты, видеоконференции и т. д.) в разы больше тех, с кем общение происходит в очной форме. Люди начинают смотреть на других людей, по выражению Ю. Харари, как на аудиовизуальных животных, которые состоят из пары глаз и пары ушей, а также пальцев для тюканья по клавиатуре и 
кредитки, оплачивающей контент и онлайн-услуги разного рода (Харари, 2019: 145).

Если раньше человек тратил много времени на поиск информации, то в условиях цифрового общества эта задача значительно упростилась и, чтобы эффективнее адаптироваться к современному миру, индивиду необходима способность отфильтровывать информацию наиболее быстрым и наименее энергозатратным способом. Индивиды, не сумевшие действенно встроиться в цифровое общество, будут испытывать стресс от распространяемых точечно агрессивного маркетинга, беззастенчивого навязывания ненужных им товаров и услуг, от ложной («фейковой») информации, граничащей с мошенничеством и киберпреступностью. Способность эффективно искать, фильтровать и анализировать информацию, работать с различными ее источниками, формирование с детства культуры работы с современным информационным потоком являются условиями успешного существования человека в цифровом обществе.

В цифровом обществе складывается «поколение с опущенной головой» - молодые люди, замкнутые в себе и на себе. Это происходит от того, что «цифровое зрение» дает больше информации об окружающем мире, чем биологическое зрение. Стиль жизни современного цифрового поколения, его манеру общения и привычки определяют социальные сети и смартфоны. Различие между мобильным телефоном и смартфоном очень существенна: со смартфона можно выходить в Интернет - для поиска нужной информации и общения в социальных сетях. С течением времени одни мессенджеры сменяют другие, но их смысл остается неизменным - замена объективной реальности цифровой, живого общения между людьми общением через цифровые приложения. Цифровое поколение начинает отдаляться от предыдущих поколений, возникают труднопреодолимые стены не(до-)понимания.

Уже сейчас современное поколение в большинстве своем не в состоянии воспринимать информацию так, как ее воспринимали их предшественники. С большим трудом цифровые молодые люди выслушивают классические полуторачасовые лекции даже самого квалифицированного преподавателя, могут прочитать объемные классические философские и литературные произведения. Учителям и преподавателям становится всё сложнее донести им информацию.

Указанные тенденции, безусловно, создают трудности и угрозы для современной системы образования. Так, студенты, которые только слушали обычные лекции, на 55\% чаще проваливали экзамен, чем те, кто еще и участвовал в обсуждении материала, пусть даже в минимальной форме. В результате сегодня многие вузы уменьшают количество лекций в пользу 
активных форм и методов работы - практических занятий, семинаров, обсуждения студенческих докладов и рефератов. Если ранее образование в первую очередь брало на себя роль источника информации, то сегодня, в формирующемся цифровом обществе, приоритет должен отдаваться обучению правильно искать, фильтровать и анализировать информацию ${ }^{1}$.

Еще одним из угрожающих проявлений цифровизации общества является выстраивание индивидуального окружения источников информации. Если раньше человек довольствовался тем, что есть радио, телевидение, газеты, то сегодня разнообразие источников позволяет ему сделать выбор в пользу тех, которые отвечают только его интересам и предпочтениям. Классические СМИ перестают соответствовать индивидуальным требованиям к темпу преподнесения и сортировке интересующей информации в виде ленты. Социальные сети и формат подписок дают возможность пользователю создать индивидуальную ленту новостной и другой информации, которая максимально адаптирована под конкретного человека, но, в свою очередь, такая возможность открывает безграничные возможности для манипулирования в чьих-то, возможно, небескорыстных интересах.

\section{Заключение}

Формирование цифрового общества в современном мире, включая Российскую Федерацию, в которой уже принят ряд правительственных документов в данной области, представляют собой концептуальный вызов для социологической теории.

Цифровая трансформация касается практически всех сфер общественной жизни. Процессы и результаты цифровизации экономики, политики, коммуникации, духовной жизни ставят перед социологией, а также всей системой российского образования новые, крайне серьёзные и в определенном смысле даже экзистенциальные задачи.

\section{СПИСОК ЛИТЕРАТУРЫ}

Деревянченко, А. А. (2019) О влиянии социальных сетей на социализацию современных детей // Актуальные проблемы гуманитарных и социально-экономических наук. М.: Изд-во «Спутник». С. 308-312.

Кузнецова, Т. Ф. (2018) Цифровое общество в свете культурологии [Элек-

\footnotetext{
${ }^{1}$ Freeman, S. (2014) Activelearning increases student performance in science, engineering, and mathematics // Proceedings of the national academy of sciences of the united states of America. [Электронный ресурс] URL: https://www.researchgate.net/publication/262267588_ Active_Learning_Increases_Student_Performance_in_Science_Engineering_and_Mathematics (дата обращения 21.10.2019).
} 
тронный ресурс] // Горизонты гуманитарного знания. № 1. C. 27-36. URL: http://journals.mosgu.ru/ggz/article/view/700 (дата обращения: 27.10.2019). DOI: $10.17805 /$ ggz.2018.1.2

Россия и вызовы цифровой среды: рабочая тетр. (2014) / [В. С. Овчинский и др.]; [гл. ред. И.С. Иванов]; Российский совет по междунар. делам (РСМД). М.: Спецкнига. 40 с.

Харари, Ю. (2019) 21 урок для XXI века. М.: Синдбад. 416 с.

Дата поступления: 12.12.2019 г.

Деревянченко Александр Алексеевич - доктор социологических наук профессор, профессор кафедры социологии Московского гуманитарного университета. Адрес: 111395, Россия, г. Москва, ул. Юности, д. 5. Тел.: +7 (499) 374-60-21. Эл. адрес: a_der@km.ru

Калинин Дмитрий Васильевич - аспирант кафедры гуманитарных и социальных наук Института инновационных технологий и государственного управления МИРЭА - Российского технологического университета. Адрес: 119454, Россия, г. Москва, пр-т Вернадского, д. 78. Тел.: +7 (499) 21565-65. Эл. адрес: торосс@mail.ru

Derevyanchenko Aleksandr Alekseyevich, Doctor of Sociology, Professor, Professor, Department of Sociology, Moscow University for the Humanities. Postal address: 5, Yunosti St., Moscow, Russian Federation, 111395. Tel.: +7(499) 37460-21. E-mail: a_der@km.ru

Kalinin Dmitriy Vasilyevich, Postgraduate Student, Department of Humanities and Social Sciences, Institute of Innovative Technologies and Public Administration MIREA - Russian Technological University. Postal address: 78, Vernadskogo Ave., Moscow, Russian Federation, 119454. Tel.: +7 (499) 215-6565. E-mail: mopocc@mail.ru

\section{Для цитирования:}

Деревянченко А. А., Калинин Д. В. Цифровое общество: новые возможности и старые угрозы [Электронный ресурс] // Научные труды Московского гуманитарного университета. 2019. № 6. URL: http://journals.mosgu.ru/trudy/article/view/1093 (дата обращения: дд.мм.гг.). DOI: 10.17805/trudy.2019.6.2 